\title{
Prenatal and Perinatal Risk Factors for Autism at National Children's Hospital
}

\author{
Bhattarai $\mathbf{A}^{1}$, Nawaraj $\mathrm{KC}^{2}$, Subedi ${ }^{1}$, Namrata $\mathrm{KC}{ }^{1}$, Bijukchhe $\mathbf{S M}^{3}$, Paudel $\mathbf{S}^{4}$ \\ 'Lecturer, Department of Pediatrics, ${ }^{3}$ Lecturer, Department of Surgery, ${ }^{4} \mathrm{BN}$ (First year nursing student) \\ Gandaki Medical College \& Teaching Hospital, Pokhara, Nepal \\ ${ }^{2}$ Consultant Pediatrician, Karnali Provinceal Hospital, Nepal
}

\section{Keywords}

Autism, Perinatal, Prenatal.

\section{Corresponding author}

*Dr. Arjun Bhattarai

Lecturer

Department of Pediatrics

Gandaki Medical Collage \& Teaching Hospital,

Pokhara, Nepal

Email:arjunbhattarai714@gmail.com

\begin{abstract}
Background: Autism, or autism spectrum disorder, refers to a broad conditions characterized by challenges with social skills, repetitive behaviors, speech and nonverbal communication.
\end{abstract}

Objectives: To determine the demographic profile of patients diagnosed with ASD, determine the significant prenatal and perinatal risk factors associated with ASD.

Results: A total of 116 subjects were included in the study with 58 cases and 58 controls. They belong to the age ranging from 4 to 16 years old. Every case had a confirmed diagnosis of autism at NCH. There was a significant association noted between neonatal jaundice, nulliparity $(\mathrm{OR}=2.38$; 95\% CI, 0.85-6.8) and family history of autism (OR=5.30; 95\% CI, 1.29-25.1) with ASD. Exposure to x-ray, medical problems, medicine intake and maternal complications during pregnancy were not significantly associated with ASD with OR 0.74; 95\% CI, (0.12-4.15), OR 1.00; 95\% CI (0.38-2.61), OR1.49; 95\% CI, (0.63-3.53), and OR 1.27; 95\% CI, (0.28-6.05), respectively.

Conclusion: The current study indicates that the only significant predictor of ASD is a family history of autism. However, neonatal jaundice, maternal age of $>40$ years old, smoking during pregnancy and nulliparity showed a trend towards being risk factors for ASD. None of the other prenatal and perinatal characteristics significantly predicts ASD.

\section{INTRODUCTION}

Autism is the prototypical form of a spectrum of related, complex neurodevelopmental disorders referred to as the autistic spectrum disorders ${ }^{1}$. There is strong evidence from neuropathological studies that ASD has its origins in abnormal brain development early in prenatal life $^{2}$. Atypical neurodevelopment continues postnatal, with a unique pattern of acceleration in brain growth as measured by head circumference ${ }^{3}$, which correlates with enlarged grey matter volumes observed in MRI studies by two to three years of age ${ }^{4}$. Advances in neonatal intensive care have dramatically increased survival in preterm infants, most strikingly among the sickest and most preterm ${ }^{5,6}$. Unfortunately, this decrease in mortality has not been matched by a comparable decrease in longterm neurodevelopmental morbidity ${ }^{7}$. Although autism is typically not diagnosed until late in the preschool years, there are marked neurodevelopmental abnormalities that are present at birth and continue to evolve from the earliest months of life. We now know that professionals can diagnose children with autism when they are as young as two years of age $\mathrm{e}^{8}$. Screening and the role of the pediatrician have become even more critical as we have recognized the stability of early diagnosis over time and the importance of early intervention.

The literature is not always consistent in regards to which 
with autism. Thus, this study is proposed to determine the prenatal and perinatal risk factors for autism at National Children Hospital, which may be helpful in identifying high-risk groups for ASD and will have significant role in early diagnosis and intervention.

\section{METHODS}

This was a case control study. The study was conducted at National Children's Hospital, a tertiary Government Hospital under the Department of Health. Cases were patients diagnosed to have Autism Spectrum Disorder at National Children Hospital. Controls were taken from patients with similar age and sex who visited the general OPD clinic. A standard pretested and validated questionnaire with presence or absence of important prenatal and perinatal risk factors was used. The questionnaire was prepared by conducting a focus group discussion with ten mothers of children diagnosed with ASD. This was further pretested and validated randomly with forty other mothers who visited our neurodevelopment and general OPD Clinic after signing of informed consent. The number of samples to be collected was computed using a 95\% level of confidence and $80 \%$ power of the study. A sample size of at least 114 was reached to detect a $13 \%$ difference in the occurrence of prematurity among cases and controls. The questionnaire was distributed among at least 57 parents of patients with ASD and 57 parents of patients visiting in general OPD. Consent was provided for all parents who allowed their children to be part of the research. All information obtained from the participants in the study would be kept confidential. Data were encoded and tallied in SPPS version 17 for windows. For nominal data, frequency and percentage were generated. For numerical data, mean +/-SD was computed. Data was analyzed using chi-square, Fisher Exact test, and logistic regression analysis.

\section{RESULTS}

A total of 116 subjects were included in the study, with equal numbers of cases and controls. Table 1 shows the association of the demographic characteristics with autism spectrum disorder (ASD). The results showed that there was a significant association noted between the number of pregnancies and family history of autism with ASD as proven by the $\mathrm{p}$ values $<0.05$ and 0.007 respectively. For the number of pregnancies, nulliparity showed a higher risk for ASD and a higher risk was noted among those with a family history of autism (OR=5. 30; 95\% CI, 1.29-25.1). On the other hand, there were no significant associations noted between age and family history of psychiatric illness with ASD as proven by all $\mathrm{p}$ value $>0.05$.

Table 1: Association of the different demographic characteristics with autism spectrum disorder (ASD)

\begin{tabular}{|c|c|c|c|c|}
\hline & $\begin{array}{l}\text { Cases } \\
(n=58)\end{array}$ & $\begin{array}{l}\text { Controls } \\
(n=58)\end{array}$ & $\begin{array}{c}\text { OR } \\
(95 \% \mathrm{CI})\end{array}$ & ${ }^{*}$ p-value \\
\hline \multicolumn{5}{|c|}{ Number of times pregnant before } \\
\hline Never & $16(27.6 \%)$ & $8(13.8 \%)$ & $2.38(0.85-6.80)$ & $0.04(S)$ \\
\hline Once & $14(24.1 \%)$ & $11(19.0 \%)$ & $0.64(0.17-2.36)$ & $0.44(\mathrm{NS})$ \\
\hline$>$ Once & $28(48.3 \%)$ & $39(67.2 \%)$ & $0.36(0.12-1.05)$ & $0.06(\mathrm{NS})$ \\
\hline \multicolumn{5}{|l|}{ Age } \\
\hline$<40 \mathrm{y} / \mathrm{o}$ & $54(93.1 \%)$ & $57(98.3 \%)$ & $0.24(0.01-2.40)$ & $0.36(\mathrm{NS})$ \\
\hline$>40 \mathrm{y} / \mathrm{o}$ & $4(6.9 \%)$ & $1(1.7 \%)$ & $\begin{array}{c}4.22(0.42- \\
102.4)\end{array}$ & $0.36(\mathrm{NS})$ \\
\hline \multicolumn{5}{|c|}{ Family history of autism } \\
\hline Yes & $13(22.4 \%)$ & $3(5.2 \%)$ & $5.30(1.29-25.1)$ & $0.007(\mathrm{~S})$ \\
\hline No & $45(77.6 \%)$ & $55(94.8 \%)$ & $0.19(0.04-0.78)$ & $0.007(S)$ \\
\hline \multicolumn{5}{|c|}{ Family history of psych illness } \\
\hline Yes & $6(10.3 \%)$ & $5(8.6 \%)$ & $1.22(0.31-4.99)$ & $1.00(\mathrm{NS})$ \\
\hline No & $52(89.7 \%)$ & $53(91.4 \%)$ & $0.82(0.20-3.32)$ & $1.00(\mathrm{NS})$ \\
\hline
\end{tabular}

Chi-square test otherwise, Fisher Exact test *p-values $>0.05$ - Not significant; $p$-values $\leq 0.05$ - Significant

Fig 2: Distribution of subjects with and without and according to the number of times pregnant before

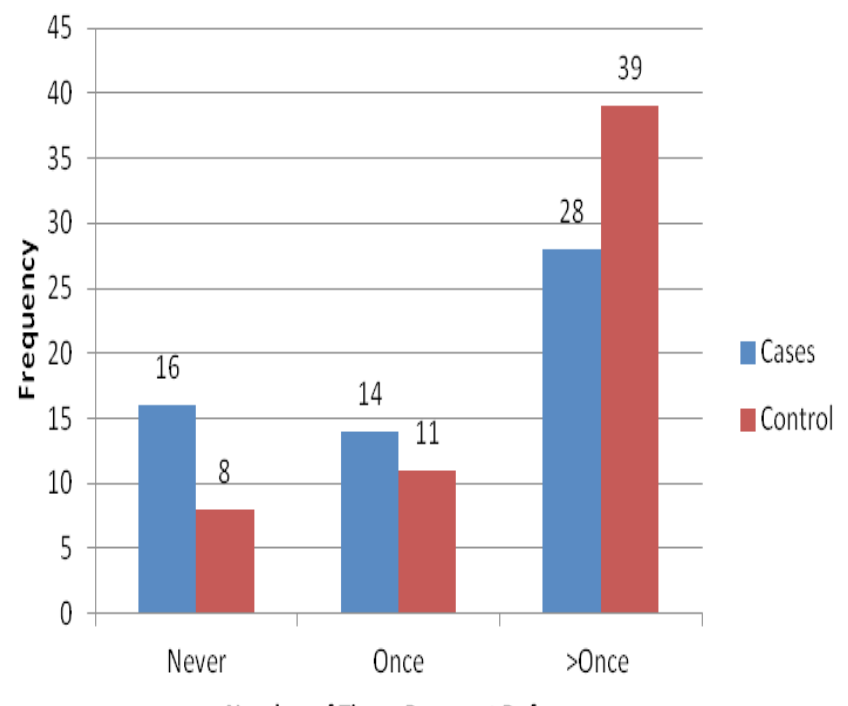

Number of Times Pregnant Before 
Fig 3: Distribution of subjects with and without ASD according family history of autism

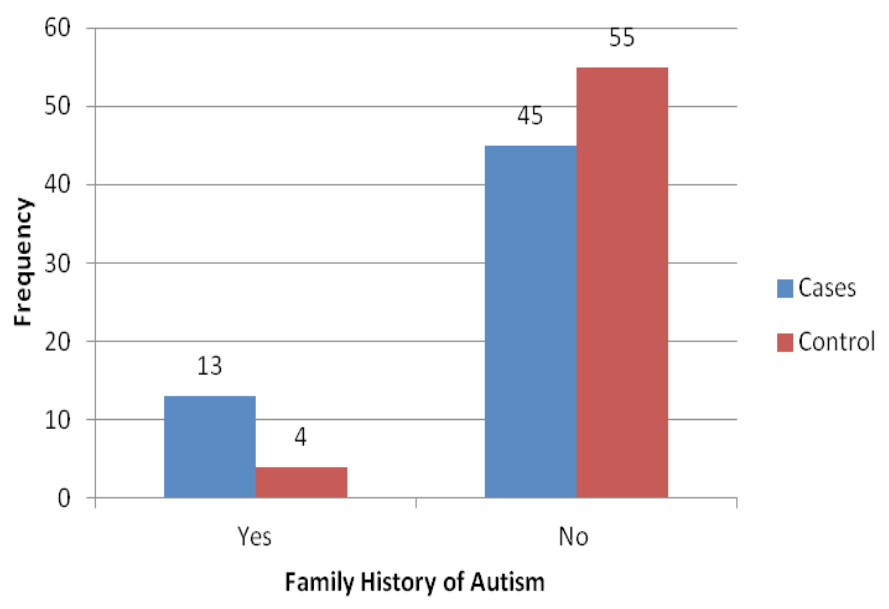

Table2, shows the association of the prenatal characteristics with ASD. Exposure to x-ray, medical problems, medicine intake, history of smoking and maternal complications during pregnancy were not significantly associated with ASD ( $>>0.05)$.

Table 2: Association of the prenatal characteristics with autism spectrum disorder (ASD)

\begin{tabular}{|c|c|c|c|c|c|}
\hline & \multicolumn{2}{|c|}{$\begin{array}{l}\text { Cases } \\
(n=58)\end{array}$} & $\begin{array}{c}\text { Controls } \\
(n=58)\end{array}$ & $\begin{array}{c}\text { OR } \\
(95 \% \mathrm{Cl})\end{array}$ & *p-value \\
\hline \multicolumn{6}{|c|}{ Smoking exposure during pregnancy } \\
\hline \multirow{2}{*}{$\begin{array}{l}\text { Yes } \\
\text { No }\end{array}$} & \multicolumn{2}{|c|}{$17(29.3 \%)$} & \multirow{2}{*}{$\begin{array}{l}21(36.2 \%) \\
37(63.8 \%)\end{array}$} & \multirow{2}{*}{$\begin{array}{c}0.73(0.31- \\
1.71)\end{array}$} & \multirow[t]{2}{*}{0.42 (NS) } \\
\hline & $41(70$ & $.7 \%)$ & & & \\
\hline \multicolumn{6}{|c|}{ Smoking during pregnancy } \\
\hline Yes & & $1(1.7 \%)$ & $5.38(0.58$ & \multirow[t]{2}{*}{0.20 (NS) } \\
\hline No & \multicolumn{2}{|c|}{$53(91.4 \%)$} & $57(98.3 \%)$ & $-125.7)$ & \\
\hline \multicolumn{6}{|c|}{ Exposed to X-ray during pregnancy } \\
\hline Yes & \multicolumn{2}{|c|}{$3(5.3 \%)$} & $4(6.9 \%)$ & \multirow{2}{*}{$\begin{array}{l}0.74(0.12- \\
4.15)\end{array}$} & \multirow[t]{2}{*}{1.00 (NS) } \\
\hline No & \multicolumn{2}{|c|}{$55(94.8 \%)$} & $54(93.1 \%)$ & & \\
\hline \multicolumn{6}{|c|}{ Medical problems during pregnancy } \\
\hline Yes & \multirow{2}{*}{\multicolumn{2}{|c|}{$\begin{array}{l}13(22.4 \%) \\
45(77.6 \%)\end{array}$}} & $13(22.4 \%)$ & $1.00(0.38$ & \multirow[t]{2}{*}{1.00 (NS) } \\
\hline No & & & $45(77.6 \%)$ & $-2.61)$ & \\
\hline \multicolumn{6}{|c|}{ Medication intake during pregnancy } \\
\hline Yes & \multirow{2}{*}{\multicolumn{2}{|c|}{$\begin{array}{l}21(36.2 \%) \\
37(63.8 \%)\end{array}$}} & $16(27.6 \%)$ & \multirow{2}{*}{$\begin{array}{c}1.49(0.63- \\
3.53)\end{array}$} & \multirow[t]{2}{*}{0.32 (NS) } \\
\hline No & & & $42(72.4 \%)$ & & \\
\hline \multicolumn{6}{|c|}{ Maternal complications during pregnancy } \\
\hline \multirow{2}{*}{$\begin{array}{l}\text { Severe } \\
\text { hyper- } \\
\text { emesis }\end{array}$} & & & & & \\
\hline & $5(8.6 \%)$ & $4(6.9 \%)$ & \multicolumn{2}{|c|}{$1.27(0.28-6.05)$} & 1.00 (NS) \\
\hline Edema & $11(19.0 \%)$ & $9(15.5 \%)$ & \multicolumn{2}{|c|}{$1.27(0.44-3.72)$} & 0.62 (NS) \\
\hline PROM & $5(8.6 \%)$ & $11(19.0 \%)$ & \multicolumn{2}{|c|}{$0.40(0.11-1.38)$} & 0.10 (NS) \\
\hline Others & 0 & $1(1.7 \%)$ & \multicolumn{2}{|c|}{$0(0-17.54)$} & 1.00 (NS) \\
\hline
\end{tabular}

Chi-square test otherwise, Fisher Exact test ${ }^{*}$ P-values $>0.05$ - Not significant; $p$-values $\leq 0.05$ - Significant
Table 3 shows the association of the perinatal characteristics with autism spectrum disorder (ASD). The results showed that there was a significant association noted between neonatal jaundice $(\mathrm{p}=0.01)$ with ASD. On the other hand, there were no significant associations noted between the other perinatal characteristics with ASD as proven by all $p$ values $>0.05$.

Table 3: Association of the perinatal characteristics with autism spectrum disorder (ASD)

\begin{tabular}{|c|c|c|c|c|}
\hline & $\begin{array}{l}\text { Cases } \\
(n=58)\end{array}$ & $\begin{array}{c}\text { Controls } \\
(n=58)\end{array}$ & $\begin{array}{c}\text { OR } \\
(95 \% \mathrm{Cl})\end{array}$ & ${ }^{*}$ p-value \\
\hline \multicolumn{5}{|c|}{ Gestational age } \\
\hline $\begin{array}{l}37-42 \\
\text { weeks } \\
<37 \text { weeks } \\
>42 \text { weeks }\end{array}$ & $\begin{array}{c}42(72.4 \%) \\
11(19.0 \%) \\
5(8.6 \%)\end{array}$ & $\begin{array}{c}49(84.5 \%) \\
8(13.8 \%) \\
1(1.7 \%)\end{array}$ & $\begin{array}{l}0.48(0.17-1.31) \\
1.60(0.53-4.88) \\
5.83(0.62-137.3)\end{array}$ & $\begin{array}{l}0.11 \text { (NS) } \\
0.35 \text { (NS) } \\
0.10 \text { (NS) }\end{array}$ \\
\hline \multicolumn{5}{|c|}{ Birth weight } \\
\hline $\begin{array}{l}\geq 2.5 \mathrm{~kg} \\
<2.5 \mathrm{~kg} \\
<1.5 \mathrm{~kg}\end{array}$ & $\begin{array}{c}50(86.2 \%) \\
6(10.3 \%) \\
2(3.4 \%)\end{array}$ & $\begin{array}{l}53(91.4 \%) \\
5(8.6 \%) 0\end{array}$ & $\begin{array}{c}0.59(0.15-2.17) \\
1.27(0.32-5.20) \\
--\end{array}$ & $\begin{array}{l}0.38 \text { (NS) } \\
0.70 \text { (NS) } \\
0.24 \text { (NS) }\end{array}$ \\
\hline \multicolumn{5}{|c|}{ Manner of delivery } \\
\hline $\begin{array}{l}\text { CS } \\
\text { NSD }\end{array}$ & $\begin{array}{l}20(34.5 \%) \\
38(65.5 \%)\end{array}$ & $\begin{array}{l}16(27.6 \%) \\
42(72.4 \%)\end{array}$ & $1.38(0.58-3.30)$ & 0.42 (NS) \\
\hline \multicolumn{5}{|c|}{ Exclusive breastfeeding for 6 months } \\
\hline $\begin{array}{l}\text { Yes } \\
\text { No }\end{array}$ & $\begin{array}{l}30(51.7 \%) \\
28(48.3 \%)\end{array}$ & $\begin{array}{l}29(50.0 \%) \\
29(50.0 \%)\end{array}$ & $1.07(0.48-2.37)$ & 0.85 (NS) \\
\hline \multicolumn{5}{|c|}{ Newborn complications } \\
\hline Apnea & 0 & $5(8.6 \%)$ & $0(0-1.12)$ & 0.05 (NS) \\
\hline $\begin{array}{l}\text { Neonatal } \\
\text { Sepsis }\end{array}$ & $2(3.4 \%)$ & $3(5.2 \%)$ & $0.65(0.07-5.08)$ & 1.00 (NS) \\
\hline $\begin{array}{l}\text { Neonatal } \\
\text { Jaundice }\end{array}$ & $7(12.1 \%)$ & 0 & --- & $0.01(\mathrm{~S})$ \\
\hline Others & $2(3.4 \%)$ & $3(5.2 \%)$ & $0.65(0.07-5.08)$ & 1.00 (NS) \\
\hline
\end{tabular}

Chi-square test otherwise, Fisher Exact test *p-values $>0.05$

- Not significant; p-values $\leq 0.05$ - Significant

Fig 4: Distribution of subjects with and without ASD according to the neonatal complications

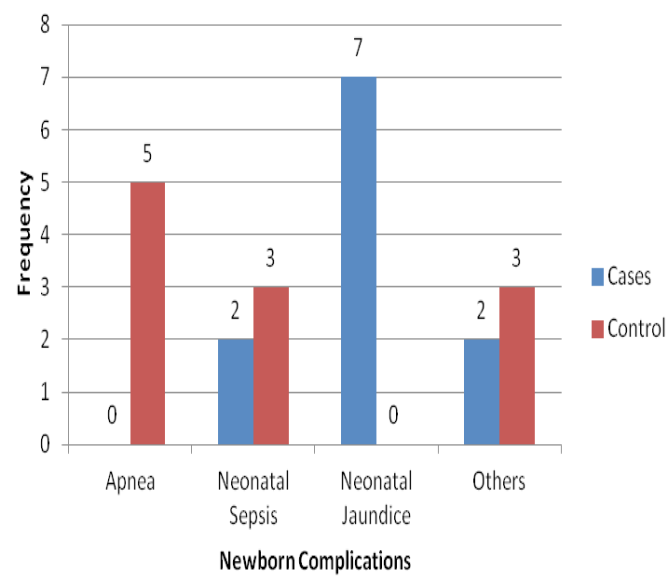


In the univariate analysis, three variables were significantly associated with ASD, namely neonatal jaundice, nulliparity and family history of autism. However, in the multivariate analysis using logistic regression, only family history of autism was the significant predictor of ASD $(p=0.02)$. The risk of subjects with a family history of autism for ASD was almost $5 \mathrm{x}$ higher than those without a family history of autism (OR=4. 72; 95\% CI, 1.20-18.54, p=0.02). In the univariate analysis, three variables were significantly associated with ASD, namely neonatal jaundice, nulliparity and family history of autism.

However, in the multivariate analysis using logistic regression, only family history of autism was the significant predictor of ASD ( $\mathrm{p}=0.02)$. The risk of subjects with a family history of autism for ASD was almost $5 \mathrm{x}$ higher than those without a family history of autism (OR=4. 72; 95\% CI, 1.20-18.54, $\mathrm{p}=0.02$ ).

Table 4: Predictors of ASD

\begin{tabular}{llll}
\hline Variable & OR & $\mathbf{9 5 \%} \mathbf{C l}$ & P value \\
$\begin{array}{l}\text { Smoking during } \\
\text { pregnancy }\end{array}$ & 7.28 & $0.81-65.90$ & $0.08(\mathrm{NS})$ \\
$\begin{array}{l}\text { Premature rupture of } \\
\text { membrane }\end{array}$ & 0.39 & $0.10-1.48$ & $0.16(\mathrm{NS})$ \\
$\begin{array}{l}\text { Abnormal AOG of baby } \\
\text { Apnea }\end{array}$ & 1.91 & $0.66-5.53$ & $0.24(\mathrm{NS})$ \\
$\begin{array}{l}\text { Neonatal jaundice } \\
\text { Number of times pregnant }\end{array}$ & 2542 & $0-4.9 \mathrm{E}+21$ & $0.72(\mathrm{NS})$ \\
$\begin{array}{l}\text { before (Never) } \\
\text { Family history of autism }\end{array}$ & $\mathbf{4 . 7 2}$ & $\mathbf{1 . 2 0 - 1 8 . 5 4}$ & $\mathbf{0 . 0 2}(\mathbf{S})$ \\
\hline
\end{tabular}

Logistic Regression Analysis

p-values $>0.05$ - Not significant;

p-values $\leq 0.05$-Significant

\section{DISCUSSION}

A case-control study, frequency-matched on gender and birth year, to investigate prenatal and perinatal risk factors for autism in our hospital was conducted. The current study determines the association between the different demographic characteristics, prenatal and perinatal factors of autism. Most of the perinatal and prenatal factors examined in multiple studies have shown inconsistent results and the preponderance of findings overall have not been statistically significant. In previous studies, the factors with the strongest evidence for an association with autism risk included abnormal fetal presentation, umbilical-cord complications, fetal distress, birth injury or trauma, multiple birth, maternal haemorrhage, summer birth, low birth weight, small for gestational age, congenital malformation, low 5-minute Apgar score, feeding difficulties, meconium aspiration, neonatal anemia, $\mathrm{ABO}$ or $\mathrm{Rh}$ incompatibility, and hyperbilirubinemia. However, not all of these factors were examined in this study. In a previous study, the strongest prenatal factors included advanced maternal and paternal age at birth, maternal gestational bleeding, gestational diabetes, being first born versus third born or later, maternal prenatal medication use, and maternal birth abroad In the present study, aside from prenatal and perinatal characteristics, the demographic characteristics were also investigated. The results showed that in the univariate analysis, family history of autism was significantly associated with ASD. Nulliparity showed trend towards being a risk factor. Several previous studies have found that ASD individuals tend to be first or fourth born more commonly than controls ${ }^{17}$. Rather than having a role in the cause of autism, this phenomenon is widely believed to be a result of alterations in the reproductive behavior of parents in response to the birth of a handicapped child, also known as the "reproductive stoppage rules"18.

Among the perinatal characteristics, neonatal jaundice $(\mathrm{p}=0.01)$ was significantly associated with ASD. In previous studies, history of jaundice in neonates was associated with increased risk of disorders of psychological development for children born at term. The excess risk of developing a disorder in the spectrum of psychological development disorders among those who had neonatal jaundice was between 56\% (HR: 1.56 [95\% confidence interval [CI]: 1.05-2.30]) and 88\% (HR: 1.88 [95\% CI: 1.17-3.02]). The excess risk of infantile autism was 67\% (HR: 1.67 [95\% CI: $1.03-2.71])^{19}$.

Multivariate analysis using logistic regression showed only family history of autism as the significant predictor of ASD. However, the tendency of smoking during pregnancy and never been pregnant before as potential risk factors for ASD was also noted. This study suggests that only family history of autism is the strongest predictor of ASD. The risk of subjects with family history of autism for ASD was almost five times higher than those without family history of autism (OR=4.72; 95\% CI, 1.20-18.54, $\mathrm{p}=0.02)$.

The finding in this study supports ASD to be a possible genetic problem. Previously, Genetic studies in the field of autistic disorder have mainly focused on molecular genetic studies, assessment of chromosomal abnormalities, twin studies and family studies. In families having an autistic child the recurrence rate has been reported as $3-8 \%{ }^{20}$. 
The studies on twins and adopted children are important in identifying the actual importance of genetic factors. Concordance among twins enables to measure heritability, and thus to assess what percentage of the phenotype is affected by genetic factors. Monozygotic (identical) twins share $100 \%$ of the genetic material, whereas dizygotic (fraternal) twins share $50 \%$ of the genetic material. Monozygotic twins higher rate of concordance compared to dizygotic twins may be used for calculation of heritability. Twin studies generally showed a higher concordance rate for monozygotic twins compared to dizygotic twins. The concordance rate of monozygotic twins is at least $60 \%$ when diagnostic criteria for autism (DSM-IV) are used, whereas the number is as high as 71\% for autism spectrum and $92 \%$ for a broader spectrum of verbal/social interaction disorders ${ }^{21}$. On the other hand, the concordance rate of dizygotic twins has been reported as $1-30 \%$. Twin studies demonstrated an average autism inheritance of $90 \%$. On the basis of these studies autism is considered to be among the most inherited psychiatric diseases.

The correlated occurrence of many of the complications limits the ability to determine which factors, if any, are independently associated with autism. For example, Cesarean deliveries are more common in pregnancies with abnormal fetal presentation, fetal distress, and multiple birth ${ }^{22,23}$. Congenital malformations, low birth weight, abnormal presentation, and low Apgar score also are interrelated ${ }^{24}$. In most studies, multivariate analyses were not used to simultaneously control for all obstetrical factors examined, and a different set of factors was examined in each study. It is possible that increasing rates of some obstetrical factors, such as Cesarean delivery, low birth weight, multiple birth, and neonatal resuscitation, may be contributing factors to the rising prevalence of autism ${ }^{25}$. The obstetrical complications that have emerged as significant risk factors for autism in a meta-analysis study suggest a possible role of fetal and neonatal hypoxia. In particular, growth retardation, fetal distress, umbilical-cord wrapping around the neck, low Apgar score, respiratory distress, resuscitation, meconium aspiration, and Cesarean delivery are all potential risk factors that also may be associated with an increased risk of hypoxia ${ }^{26}$. Although some brain abnormalities observed in individuals with autism may reflect a potential role of oxygen deprivation during development, this possibility requires additional examination. Hypoxia also has been shown to increase dopaminergic activity,and there is evidence for dopamine overactivation in autism ${ }^{27}$.
However in this study related obstetrical problems like exposure to x-ray, medical problems, medicine intake and maternal complications during pregnancy were not significantly associated with ASD with OR 0.74; 95\% CI, (0.12-4.15), OR 1.00; 95\% CI (0.38-2.61), OR 1.49; 95\% CI, (0.63-3.53), and OR 1.27; 95\% CI, (0.28-6.05) respectively. Our study indicates that among the prenatal and perinatal risk factors only family history of autism is a significant predictor of ASD. None of the other prenatal and perinatal characteristics significantly predicts ASD.

\section{CONCLUSION}

The current study indicates that the only significant predictor of ASD is a family history of autism. However, neonatal jaundice, maternal age of $>40$ years old, smoking during pregnancy and nulliparity showed a trend towards being risk factors for ASD. None of the other prenatal and perinatal characteristics significantly predicts ASD.

\section{REFERENCES}

1. American Psychiatric Association, Bryson and Smith, 1998; Bertrand, et al. 2001, Chakrabarti and Fombonne, 2001; Behavioral manifestations of autism in the first year of life. Int J Devl Neuroscience. 2005; 23: 143-152.

2. Bauman and Kemper, 2003; Rodier, 2002; Autism: Genes, anatomy and behavioural outcome. JNEUROSCI. 2006; 1712-06.

3. Courchesne et al. 2003; Lainhart et al. 1997: Head circumference and height in autism. Autism Spectrum Disorders.

4. Courchesne et al. 2001; Courchesne et al. 2003. Autism spectrum disorders through the life span. Autism Spectrum Disorders.

5. Fred R Volkmar, Sally J Rogers, Rhea Paul, Kevin A Pelfrey: Handbook of Autism and Pervasive Developmental Disorders, Vol 2. 
6. Dr Saroj Saigal MD, FRCP(C), Department of Pediatrics, McMaster University, Hamilton, Ontario, Canada; Follow-up of very low birth weight babies to adolescence. Semin Neonatol. 2000; 5(2): 107-118.

7. Viena Tommiska, Kirsti Heinonen, Liisa Lehtonen, Martin Renlund, Timo Saarela. No improvement in outcome of nationwide extremely low birth weight infant populations between 1996-1997 and 19992000. Pediatrics. 2007; Vol-119(1): 29-36.

8. Grace J Hao, Steve An Xue, Janet Cheng Yan Ki, Luc de Schepper. The University of Hong Kong, Division of Speech and Hearing Sciences, Pre-natal and perinatal risk factors for autism in China.

9. Guillermo Montes, Jill S. Halterman. Association of childhood autism spectrum disorders and loss of family income. Pediatrics. April 2008; 121(4). Pediatrics, aap Publications

10. Michael E. Msall, The limits of viability and the uncertainty of neuroprotection: Challenges in optimizing outcomes in extreme prematurity. Pediatrics. 2007; 119 (1): 158-160.

11. Bailey A, Le Couteur A, Gottesman I, Bolton P, Simonoff E, Yuzda E, Rutter M. Autism as a strongly genetic disorder: Evidence from a British twin study. Psychol Med. 1995; 25: 63-77.

12. Lee, Young-A, Goto, Yukiori. The effects of prenatal and postnatal environmental interaction: Prenatal environmental adaptation hypothesis. Journal of Physiology, Paris. 2013; 107(6): 483-492.

13. Pasamanick B, Rogers ME, Lilienfeld AM; Pregnancy experience and the development of behavioral disorders in children. AMJ Psychiatry. 1956; 112:613

14. Mark A Hanson, Peter D Gluckman. Developmental origins of health and disease: New insights. Basic Clin Pharmacol Toxicol. 2008; 102: 90.

15. Gardener H, Spiegelman D, Buka SL. Prenatal risk factors for autism: A comprehensive meta-analysis. Br J Psychiatry. 2009; 195(1): 7-14.
16. Dietert RR, DeWitt J, Germolec DR, Zelikoff JT. Breaking patterns of environmentally-influenced disease for health risk reduction: Immune perspectives. Environ Health Perspect. 2010; 188: 1091-91.

17. Deykin EY, MacMahon B. Pregnancy, delivery, and neonatal complications among autistic children. Am J Disabled Child. 1980; 134: 860-864.

18. Jones MB, Szatmari P. Stoppage rules and genetic studies of autism. J Autism Dev Disord. 1988; 18:3140; Paediatrics. 2010; 126: 872.

19. Rikke Damkjaer Maimburg, Bodil Hammer Bech. Neonatal jaundice, autism, and other disorders of psychological development.

20. Shao Y, Wolpert CM, Raiford KL, Menold MM, Donnelly SL, Ravan SA, et al. Genomic screen and follow-up analysis for autistic disorders. Am J Med Genet. 2002; 114: 99-105.

21. Newschaffer CJ, Fallin D, Lee NL. Heritable and nonheritable risk factors for autism spectrum disorders. Epidemiol Rev. 2002; 24: 137-153.

22. Incerpi MH. Operative delivery. In DeCherney $\mathrm{AH}$, Nathan L, eds. Current Diagnosis and Treatment Obstetrics and Gynecology, 10th Edition. New York, NY: McGraw-Hill; 2007, pp 445- 476.

23. Martin JA, Hamilton BE, Ventura SJ, Menacker F, Park MM. Births: final data for 2000. National Vital Statistics Reports. 2002; 50(5): 1-104.

24. Maimburg RD, Vaeth M. Perinatal risk factors and infantile autism. Acta Psychiatr Scand. 2006; 114(4): 257-264.

25. Kolevson A, Gross R, Reichenberg A. Prenatal and perinatal risk factors for autism: A review and integration of findings. Arch Pediatr Adolesc Med. 2007; 161(4): $326-333$. 
26. Matsuishi T, Yamashita Y, Ohtani Y, et al. Brief report: Incidence of and risk factors for autistic disorder in neonatal intensive care unit survivors. J Autism Dev Disorder. 1999; 29(2): 161-166.

27. Previc FH. Prenatal influenced on brain dopamine and their relevance to the rising incidence of autism. Med Hypotheses. 2007; 68(1): 46-60. 